\title{
M\&S highlight: Di Benedetto et al. (2004), Fatigue of bituminous mixtures
}

\author{
Bernhard Hofko (1)
}

Received: 20 October 2021 / Accepted: 16 December 2021/Published online: 21 January 2022

(C) The Author(s) 2022

\section{Background}

Bituminous mixtures or asphalt mixtures are a composite material of bituminous binder, mineral aggregates and air voids. Bituminous mixtures are the most common construction material for road pavements, i.e. asphalt pavements. By far more than $90 \%$ of paved roads are made from bituminous mixtures, which are compacted to layers and have served as the load carrying structure for transport infrastructure for more than 100 years. Due to the cyclic nature of wheel loading by vehicles traveling on these pavements, their design is based on fatigue resistance of the structure. Since bitumen is a complex organic material resulting from crude oil refining, its mechanical properties are different from many other construction materials. The reaction to loading is highly temperature- and loadingtime-dependent viscoelastic. It exhibits liquid-like, viscous features at high temperature and low frequency of cyclic loading and solid-like, elastic

This commentary is part of our celebration of 75 years of RILEM, highlighting Materials and Structures most highly influential and cited publications.

Highlighted paper: Di Benedetto, H. et al. Fatigue of bituminous mixtures. 2004 Material and Structures. 37(3), pp. 202-216.

B. Hofko $(\bowtie)$

Institute of Transportation, TU Wien, Wien, Austria

e-mail: bernhard.hofko@tuwien.ac.at features at low temperatures and high frequencies of loading. Thus, mechanical analysis of such materials is a complex task that needs to take these material properties into account.

The highlighted paper [1] contributes to fatigue testing of bituminous materials in a fundamental way, since it compares different classes of fatigue tests with different modes of loading by detailed analysis of recorded test data and interpretation of results by different models.

\section{Milestones}

The highlighted paper was produced by the RILEM TC 182-PEB "Performance testing and evaluation of bituminous materials", in which research teams from 16 countries from Asia, Australia, North America and Europe were actively involved. At the first glance, this paper sums up efforts from an interlaboratory test campaign to assess the fatigue phenomenon of bituminous mixtures. However, if you take a little more time and study the paper in detail, it is a very densely woven source of findings that cover the experimental analysis and modelling of fatigue of viscoelastic materials in great depth. Concepts and theses presented by the authors have initiated a wide range of research projects and technical committees in this area that affect our work in this field up until now (e.g. [2-10] and will continue to do so for decades to come. 
The study presents results from five classes of fatigue tests with stress- and strain-controlled mode. Besides the classical fatigue criterion, other concepts are introduced by taking the dissipated energy into account. A thorough analysis of the evolution of stiffness vs. the number of load cycles is given, providing theses on the influence of energy dissipation and thixotropic in the initial phase of fatigue tests. A model to differentiate between the second phase (micro-crack development) and third phase (macrocrack propagation) of a fatigue test is presented. Possible reasons for differences in results between the analysed test classes are given on the basis of sound mechanical explanations. Five different damage models are compared to explain the evolution of fatigue. Two of the models introduce the concept of healing ([11-14]), which has been an important topic ever since. Maybe most importantly, the work presented in this paper is a perfect example of pre-standardization. The findings of the paper were used subsequently to develop a European Standard for fatigue testing of bituminous mixture, EN 12,697-24.

\section{Follow-up Research}

Research into bituminous materials has a long tradition within RILEM, starting in the 1960s with one of the first RILEM TCs "017-BM: Bitumens and bituminous materials". The highlighted paper, which was published in 2004, and the work of the respective TC is the basis for research in many subsequent TCs: an indepth analysis of cracking and healing in two TCs (TC 241-MCD, TC 278-CHA), the impact on asphalt pavement recycling in one TC (TC 264-RAP) and on secondary materials in bituminous mixtures in another TC (TC 279-WMR).

\section{Impact on the construction practice}

The results and findings of the highlighted paper provided a sound basis for the European Standardization Committee (CEN) to develop a testing standard for fatigue testing of bituminous mixtures. EN 12697-24 was first published in 2004 and is a centrestone in the performance-based approach for contracts in road engineering. Together with modern testing standards for resistance to permanent deformation, resistance to low-temperature cracking and stiffness testing, assessing the fatigue resistance is now implemented in many national standards, like in the Netherlands and Austria. By implementing these state-of-the-art, performance-based test methods into routine quality control testing, road infrastructure becomes more durable and thus, more sustainable.

In addition, standardized fatigue testing is now available to derive input parameters for state-of-theart Mechanistic-Empirical Pavement Design Guidelines (MEPDG). More and more countries move away from inefficient model asphalt data for their design procedures and implement performance-based tests as the basis to obtain input data from actual bituminous mixtures [15]. Thus, pavement design becomes more efficient, valuable raw materials are used in a sustainable way and innovative products can be taken into account already in the stage of pavement design. None of this would be available without fundamental work like the example presented in the highlighted paper.

\section{Quo Vadis}

The fatigue phenomenon is a complex matter by itself. When it targets bituminous materials, the viscoelastic material behaviour adds another layer of complexity. Following up on the research carried out by the highlighted papers, studies have looked into the matter of energy dissipation [16], thixotropic [17] and how to separate these non-fatigue related phenomena in the fatigue assessment [18]. In addition, fatigue is now also studied on smaller length scales, i.e. on the binder and mastic level. New test methods have been developed based on the dynamic shear rheometer (DSR) [19] to increase our knowledge on this level of observation and efforts in modelling aim at linking fatigue on the binder and mastic level to the asphalt mixture level. Healing is in the centre of attention of many studies to understand its fundamentals in bituminous materials and how healing can be correctly addressed in experimental analysis [17, 20]. Additives are developed to support healing in pre-damaged asphalt pavements. It may seem like a paradox, but the more we understand fatigue of bituminous mixtures, the further is our (personal fatigue) endurance in this complex, yet exciting field pushed to its limits and far beyond. 
Funding Open access funding provided by TU Wien (TUW).

Open Access This article is licensed under a Creative Commons Attribution 4.0 International License, which permits use, sharing, adaptation, distribution and reproduction in any medium or format, as long as you give appropriate credit to the original author(s) and the source, provide a link to the Creative Commons licence, and indicate if changes were made. The images or other third party material in this article are included in the article's Creative Commons licence, unless indicated otherwise in a credit line to the material. If material is not included in the article's Creative Commons licence and your intended use is not permitted by statutory regulation or exceeds the permitted use, you will need to obtain permission directly from the copyright holder. To view a copy of this licence, visit http://creativecommons.org/licenses/by/4.0/.

\section{References}

1. Di Benedetto H et al (2004) Fatigue of bituminous mixtures. Mater Struct 37(3):202-216

2. Fussl J, Lackner R (2011) Multiscale fatigue model for bituminous mixtures. Int J Fatigue 33(11):1435-1450

3. Li N et al (2013) Characterization of fatigue performance of asphalt mixture using a new fatigue analysis approach. Constr Build Mater 45:45-52

4. Tapsoba $\mathrm{N}$ et al (2015) Three-dimensional analysis of fatigue tests on bituminous mixtures. Fatigue Fract Eng Mater Struct 38(6):730-741

5. Hofko B (2015) Combining performance based lab tests and finite element modeling to predict life-time of bituminous bound pavements. Constr Build Mater 89:60-66

6. Isailovic I, Wistuba MP, Falchetto AC (2017) Influence of rest period on asphalt recovery considering nonlinearity and self-heating. Constr Build Mater 140:321-327

7. Zofka A, Maliszewski M, Maliszewska D (2017) Glass and carbon geogrid reinforcement of asphalt mixtures. Road Mater Pavement Des 18:471-490

8. Hernandez-Fernandez N, Underwood BS, Ossa-Lopez A (2020) Simulation of the asphalt concrete stiffness degradation using simplified viscoelastic continuum damage model. Int J Fatigue 140:105850
9. Ragni D et al (2020) Analysis of shear-torque fatigue test for bituminous pavement interlayers. Constr Build Mater 254:119309

10. Poulikakos LD, Hofko B (2020) A critical assessment of stiffness modulus and fatigue performance of plant produced asphalt concrete samples using various test methods. Road Mater Pavement Des 22(11):2661-2673

11. Little DN, Bhasin A (2007) Exploring mechanism of healing in asphalt mixtures and quantifying its impact. Self Heal Mater Altern. Approach 20 Centuries Mater Sci 100:205-218

12. Grossegger D (2021) Fatigue damage self-healing analysis and the occurrence of an optimal self-healing time in asphalt concrete. J Mater Civ Eng 33(6):04021098

13. Garcia A et al (2014) The model for induction-healing asphalt concrete. Asphalt Pavements 1-2:1431-1440

14. Leegwater G, Scarpas T, Erkens S (2016) Direct tensile test to assess healing in asphalt. Transp Res Rec 2574:124-130

15. Eberhardsteiner L, Blab R (2019) Design of bituminous pavements - a performance-related approach. Road Mater Pavement Des 20(2):244-258

16. Pouget $\mathrm{S}$ et al (2012) Viscous energy dissipation in asphalt pavement structures and implication for vehicle fuel consumption. J Mater Civ Eng 24(5):568-576

17. Canestrari F et al (2015) Modeling and assessment of selfhealing and thixotropy properties for modified binders. Int $\mathrm{J}$ Fatigue 70:351-360

18. Di Benedetto H, Nguyen QT, Sauzeat C (2011) Nonlinearity, heating, fatigue and thixotropy during cyclic loading of asphalt mixtures. Road Mater Pavement Des 12(1):129-158

19. Hospodka M, Hofko B, Blab R (2018) Introducing a new specimen shape to assess the fatigue performance of asphalt mastic by dynamic shear rheometer testing. Mater Struct 51(2): $1-11$

20. Santagata E et al (2013) Evaluation of self healing properties of bituminous binders taking into account steric hardening effects. Constr Build Mater 41:60-67

Publisher's Note Springer Nature remains neutral with regard to jurisdictional claims in published maps and institutional affiliations. 